\title{
ANALISIS MAKNA SIMBOLIK PADA PAKAIAN PENGANTIN ADAT LAMPUNG PEPADUN
}

\author{
Suyatno $^{1}$, Rinezia Putri Lelapari ${ }^{2}$ \\ Program Studi Desain Komunikasi Visual, \\ Fakultas Bahasa dan Seni, Universitas Indraprasta PGRI \\ Jl. Nangka No. 58 C, Tanjung Barat, Jakarta Selatan, 12530, Indonesia
}

Email: suyatnosyt3@gmail.com

\begin{abstract}
Abstrak
Menikah adalah ikatan janji suci antara pria dan wanita. Dalam prosesi pernikahan, masyarakat Pepadun memiliki aturan tertentu dalam berpakaian atau mengenakan atribut sesuai dengan adat istiadat. Karya ilmiah ini membahas tentang makna simbolik pada busana pernikahan masyarakat Pepadun. Tujuan penelitian ini adalah untuk mengetahui lebih dalam budaya dan kekayaan masyarakat Lampung, khususnya gaya berpakaiannya. Metode yang digunakan dalam penelitian ini adalah metode deskriptif analisis dengan pendekatan kualitatif, yaitu dengan mengumpulkan beberapa artikel dan literatur yang berhubungan dengan pakaian pengantin masyarakat Pepadun. Hasil penelitian ini menunjukkan adanya makna simbolik dari pakaian atau atribut yang dikenakan pada pakaian adat Pepadun, seperti: simbol bahwa provinsi Lampung dikelilingi sembilan sungai besar, derajat seseorang, simbol kedamaian, melindungi dari hal-hal yang jahat, terhindar dari berbagai penyakit, ikatan keluarga, menyempurnakan ibadah (pernikahan), membersihkan raga, dan kebebasan berpendapat.
\end{abstract}

Kata Kunci: Masyarakat Pepadun, Pernikahan, Pakaian Adat.

\begin{abstract}
Marriage is a sacred bond of promise between a man and a woman. In the wedding procession, the pepadun community has certain rules in dressing or wearing attributes according to customs. This scientific work deals with the symbolic significance of the pepadun wedding dress. The purpose of this study is to learn more about the culture and wealth of the sunken people, especially in their fashion. The method used in the study is a qualitative analytical method, collecting some articles and literature relating to the bridal dress of the pepadun community. The results of this study suggest a symbolic meaning to clothing or attributes that are put on pepadun's tribal clothing, such as: a symbol that a lampung province is surrounded by nine great rivers, one's degrees, a symbol of peace, protecting against evil things, being freed from various diseases, family ties, polishing worship, and freedom of speech.
\end{abstract}

Keywords: Pepadun Society, Marriage, Traditional Clothes, Marriage

Correspondence author: Suyatno, suyatnosyt3@gmail.com, Jakarta, and Indonesia 


\section{PENDAHULUAN}

Pernikahan adalah upacara pengikatan janji nikah yang dirayakan atau dilaksanakan oleh dua orang dengan maksud meresmikan ikatan perkawinan secara norma agama, norma hukum, dan norma sosial. Upacara pernikahan memiliki banyak ragam dan variasi menurut tradisi suku bangsa, agama, budaya, maupun kelas sosial. Penggunaan adat atau aturan tertentu kadang-kadang berkaitan dengan aturan atau hukum agama tertentu pula (Andriansyah, 2017).

Oleh karena itu, pernikahan menjadi suatu resepsi yang cukup sakral, agung, dan monumental bagi setiap pasangan. Di Indonesia, upacara pernikahan sangat beragam prosesnya. Ada yang dilaksanakan dengan gaya tradisional mengikuti budaya dan adat leluhur, ada juga yang merayakan dengan konsep kekinian/modern.

Menggelar acara pernikahan dengan konsep budaya lokal sudah menjadi tradisi umum bagi masyarakat Indonesia. Seperti yang kita ketahui, Indonesia memiliki beragam suku dan budaya, maka tidak heran apabila kita sering menjumpai upacara-upacara adat yang sangat unik. Biasanya pengantin atau mempelai melangsungkan acara pernikahannya dengan adat-istiadat dari asal suku masing-masing mempelainya, ada yang menggunakan dua adat sekaligus karena masing-masing mempelai berasal dari suku yang berbeda, namun ada juga yang melangsungkan pernikahan menggunakan adat yang kedua mempelainya tidak ada hubungannya dengan adat tersebut, namun karena alasan tertentu seperti keunikannya, keindahannya, dan sebagainya membuat mereka tertarik untuk menggunakan adat tersebut (Andriansyah, 2017).

Berbicara pernikahan tentu tidak terlepas dari busana yang dikenakan. Indonesia memiliki budaya, suku, ras, dan adat yang beragam. Busana yang dikenakan saat acara pernikahan mewakili daerah asal si mempelai. Setiap balutan busana pernikahan memiliki keunikan, ciri khas, nilai, dan makna yang mendalam. Sama halnya dengan pernikahan yang dilaksanakan oleh pengantin asal Lampung. Salah satu provinsi bagian selatan di Pulau Sumatera.

Masyarakat Lampung asli memiliki struktur hukum adat tersendiri. Bentuk hukum tersebut berbeda antara kelompok masyarakat yang satu dengan yang lainnya. Secara umum, kelompok-kelompok tersebut dapat dibedakan menjadi dua bagian, yaitu masyarakat Saibatin dan Pepadun. Lampung dikenal dengan sebutan Sai Bumi Khua Jukhai, secara bahasa artinya yaitu Satu Bumi Dua Cabang, sedangkan berdasarkan makna yaitu Sai Bumi artinya satu bumi, bermakna suku bangsa yang mendiami satu wilayah yang berasal dari keturunan yang sama, dan Khua Jukhai dua cabang, bermakna dua jenis adat istiadat yang dikenal di kalangan masyarakat. Dari semboyan di atas, kita mengenal dua adat istiadat yang ada pada masyarakat Lampung, yaitu Saibatin dan Pepadun.

Bila dilihat dari wilayah teritorialnya, masyarakat adat Saibatin berkediaman di sepanjang pesisir Lampung, seperti Kerajaan Sekala Beghak di Lampung Barat dan Pesisir Barat, Ranau Komering, Tanggamus, sebagian Pringsewu, sebagian Pesawaran, Keratuan Darah Putih Lampung Selatan, dan Keratuan Melinting Lampung Timur. Kemudian, masyarakat adat Pepadun berkediaman di daerah pedalaman Lampung, seperti Lampung Tengah, Lampung Utara, Way Kanan, Tulang Bawang, Tulang Bawang Barat, sebagian Pesawaran, sebagian Pringsewu, dan sebagian Mesuji. Daerah tersebut terdiri dari masyarakat adat Abung (Abung Siwo Migo), Pubian (Pubian Telu Suku), Menggala / TulangBawang (Migo Pak) dan Buai Lima (Andriansyah, 2017).

Pakaian adat Lampung merupakan salah satu peninggalan budaya yang khas dan memiliki nilai seni yang tinggi. Masyarakat Lampung memiliki pakaian adat pernikahan dengan keunikannya sendiri. Terdapat dua adat istiadat yang berbeda di Lampung, yaitu Saibatin dan Pepadun. Saibatin berarti Satu Penguasa (Raja), sedangkan Pepadun berarti Tempat Duduk Penobatan Penguasa. Meskipun sama-sama Lampung, keduanya memiliki perbedaan dan ciri khasnya masing-masing, seperti bahasa, kebiasaan, tatanan adat, dan tak terkecuali dalam gelaran pernikahan adatnya (Andriansyah, 2017). Penelitian ini bertujuan untuk menggali lebih dalam mengenai makna simbolik pada pakaian pengantin masyarakat Lampung, khususnya Pepadun. 
Pakaian adat merupakan simbol suatu daerah atau suku dan biasa dipakai pada upacaraupacara adat untuk memperingati hari besar, seperti kelahiran, pernikahan, kematian, pesta panen, dan lain sebagainya. Setiap suku atau daerah biasanya memiliki pengertian pakaian adatnya sendiri, bahkan sering dijadikan sebagai simbol untuk menandakan sesuatu. Ciri khas yang tercermin dari bentuk, motif ornamen, dan makna simbolik yang terkandung di dalam aksesori tradisional menunjukkan tingkat perkembangan kebudayaan suku bangsa tersebut. Masyarakat Lampung secara turun-temurun telah mewarisi keterampilan yang maju dalam pembuatan aksesori tradisional khas daerahnya. Aksesori atau perhiasan tersebut berfungsi sebagai penambah nilai estetika, untuk memperindah penampilan pemakainya. Selain estetika, aksesori tradisional memiliki fungsi sosial, memberi ciri terhadap stratifikasi atau status sosial si pemakainya di tengah masyarakat. Di samping itu, aksesori tradisional juga memiliki fungsi simbolik. Aksesori yang dikenakan memberikan pesan tersirat dan makna simbolik tertentu, khususnya dalam ritual adat. Dari ketiga fungsi tersebut, pakaian dan aksesori tradisional Lampung memiliki karakter yang lebih menonjol dalam fungsi sosial serta fungsi simboliknya. Hal ini dapat dilihat dari aksesori yang digunakan dalam prosesi pernikahan adat Lampung, setiap aksesori memiliki makna simbolik yang spesifik. Jadi, pakaian adat dalam penelitian ini adalah pakaian beserta aksesori-aksesori lainnya yang dikenakan dalam upacara pernikahan adat (Andriansyah, 2017).

Alasan peneliti membahas objek ini adalah untuk memperkenalkan budaya dan kekayaan Indonesia yang belum banyak diketahui. Meskipun pakaian adat Lampung (khususnya untuk acara pernikahan) ini sudah sering dilihat, tetapi belum tentu masyarakat tahu makna/arti mendalam tentang busana dari masyarakat Pepadun ini, seperti pada bagian kalung papan jajar, kalung buah kukum, selempang pinang, ikat pinggang bulu serti, gelang burung, gelang kano, gelang bibit, siger, seraja bulan, subang, dan perhiasan pada dada, leher, pinggang, serta lengan.

\section{METODE PENELITIAN}

Metode yang peneliti gunakan dalam penelitian ini adalah metode penelitian kualitatif. Peneliti menggunakan metode penelitian kualitatif dikarenakan terdapat banyak sumber sekunder (seperti: e-book, jurnal, artikel ilmiah, skripsi, dan lain sebagainya) terkait pakaian pengantin adat Lampung, khususnya masyarakat Pepadun.

Selain itu, sifat dari pendekatan kualitatif yang mengatakan bahwa realitas bersifat ganda, rumit, dinamis, dan kebenaran realitas bersifat dinamis (Mulyana, 2013:147). Penelitian kualitatif adalah proses penelitian dan pemahaman yang didasarkan pada metodologi yang menyelidiki suatu fenomena sosial dan masalah manusia. Pada pendekatan ini, peneliti membuat suatu gambaran kompleks, meneliti kata-kata, laporan terinci dari pandangan responden, dan melakukan studi pada situasi yang alami (Creswell, 1998:15).

Untuk melaksanakan penelitian ini, peneliti menggunakan penelitian studi literatur atau pendekatan kualitatif yang pada proses penulisannya bersumber dari beberapa artikel, jurnal, gambar, video dan atau dokumentasi yang terkait dengan pakaian pengantin adat Lampung, khususnya masyarakat Pepadun. Data-data yang telah diperoleh kemudian dianalisis dan diorganisasikan. Semua data yang didapat harus benar-benar valid karena potensi yang sangat besar untuk mengetahui kesimpulan data penelitian yang dihimpun. Tidak kalah penting mengelompokkan data penelitian, memberikan deskripsi data pada hasil penelitian, menganalisis dan menginterpretasikan hasil analisis data, serta menyimpulkan hasil analisis data.

\section{HASIL DAN PEMBAHASAN}

Pernikahan adalah suatu perjanjian yang kuat dan kokoh untuk hidup bersama secara sah antara seorang laki-laki dengan seorang perempuan dengan tujuan membentuk keluarga yang kekal, santun menyantuni, kasih-mengasihi, mendapatkan garis keturunan, menjalani ibadah, tentram dan bahagia (Ramulyo, 1996). Dalam melaksanakan resepsi pernikahan, masyarakat Lampung memiliki pakaian adat yang sangat unik. Bukan sekedar hiasan semata, berbagai aksesori yang dikenakan mengandung nilai-nilai penting dan sarat makna. 
Masyarakat Lampung secara garis besar dan dari segi adat istiadatnya terbagi menjadi dua, yakni Lampung Pepadun dan Pesisir/Peminggir/Saibatin. Sebutan Peminggir atau Pesisir di sini adalah mayoritas anggota mereka berdomisili di daerah pantai di sepanjang Teluk Lampung, mulai dari barat, selatan, dan bagian sebelah timur (Khalik, 2003). Penelitian ini berfokus pada penjelasan mengenai makna simbolik yang terdapat pada pakaian adat Pepadun. Simbolik yaitu bersifat melambangkan sesuatu (Effendy, 1989). Simbolik berasal dari bahasa Latin: symbolic(us) dan bahasa Yunani: symbolicos. Simbolik biasanya berkaitan erat dengan suatu benda atau hal lain yang di dalamnya memiliki nilai, makna, atau pesan yang ingin disampaikan.

Pakaian adat Lampung Pepadun merupakan salah satu aset budaya nasional. Pakaian adat tersebut menjadi kebanggaan tersendiri bagi masyarakat Lampung Pepadun karena memiliki nilai-nilai penting dari leluhur mereka. Sebagai bentuk penghormatan terhadap peninggalan budaya tersebut, sampai saat ini pakaian adat Pepadun masih sering digunakan dalam acara pernikahan atau seni tari. Tentunya hal ini dilakukan untuk menjaga, membina, serta melestarikan budaya dan bahasa lokal mereka. Berdasarkan data atau literatur yang peneliti temukan, dapat diketahui bahwa pakaian adat Pepadun tenyata memiliki makna simbolik dibaliknya.

\section{Filosofi Pakaian Adat Pepadun} n.d.):

Beberapa perangkat pakaian pengantin adat Pepadun, antara lain (Oyos Saroso HN,

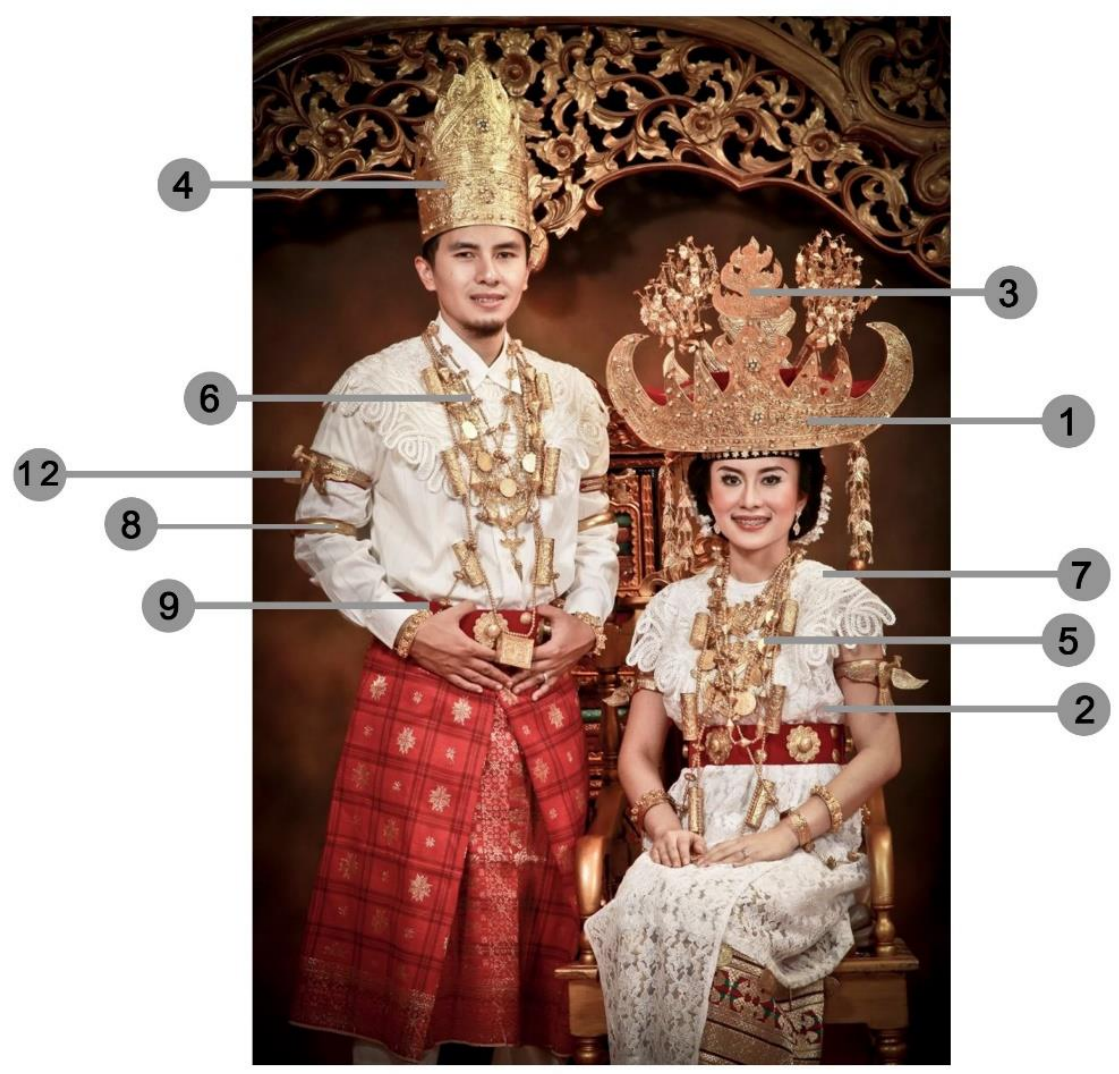

Gambar 1 Pakaian Adat Pepadun 
Keterangan gambar:

1. Siger

2. Sesapur

3. Serajo Bulan

4. Kopiah Emas

5. Bulan Temenggal

6. Buah Jukun
7. Bebe

8. Gelang Kano

9. Bulu Serati dan Pending

12. Gelang Burung

\section{Siger}

Siger merupakan mahkota yang biasa digunakan oleh mempelai wanita. Mahkota yang terbuat dari kuningan ini berbentuk seperti tanduk dan ditatah hiasan bertitik-titik menyerupai bunga. Memiliki ruji tajam berjumlah sembilan di bagian depan dan belakang. Setiap lekukannya diberi hiasan bunga cemara dari kuningan (beringin tumbuh). Puncak siger diberi hiasan serajo bulan, yaitu kembang hias berupa mahkota berjumlah satu sampai tiga buah. Mahkota kecil ini mempunyai lengkungan di bagian bawah dan beruji tajam-tajam pada bagian atas serta berhiaskan bunga.

Makna dan filosofi siger (mahkota wanita Lampung) memiliki jurai sembilan artinya suku pertama yang menempati Lampung ada sembilan gelombang atau kelompok. Selain itu, ada makna lain yaitu Lampung dialiri sembilan sungai besar, yakni Wai Semangka, Wai Sekampung, Wai Seputih, Wai Pangubuan, Wai Abung Sarem, Wai Sungkai, Wai Kanan, Wai Tulangbawang, dan Wai Mesuji. Secara garis besar, banyak sungai yang ada di Provinsi Lampung. Namun hanya sembilan nama sungai terbesar dan terpanjang saja yang masuk dalam filosofi siger.

\section{Sesapur}

Sesapur merupakan baju kurung berwarna putih, sisinya tidak berangkai, dan dihiasi uang perak yang digantung berangkai (rambai ringgit).

\section{Serajo Bulan}

Serajo bulan adalah bunga hias berupa mahkota kecil, terbuat dari kuningan, dan yang biasa dipasang di atas siger. Biasanya, ada satu hingga tiga buah serajo bulan yang dipasang di atas siger. Serajo bulan memiliki lengkungan di bagian bawah dan ruji-ruji tajam pada bagian atas dengan hiasan motif bunga. Jika dipasang di atas siger, serajo bulan akan menjadi puncak siger.

Serajo bulan memiliki makna bulan berkedudukan yang tinggi, menunjukkan si pemakai memiliki kedudukan yang tinggi dalam adat istiadat dan juga dalam lingkungan keluarga. Selain itu juga sebagai pengingat bahwa dahulu ada lima kerajaan yang sempat berkuasa di Lampung, yaitu kerajaan Ratu dibalau, Ratu dipuncak, Ratu dipugung, Ratu dipemanggilan, dan Ratu darah putih. Selanjutnya, filosofi lain bahwa melambangkan lima falsafah hidup masyarakat Lampung di antaranya piil sengiri 'rasa harga diri', nemui nyimah 'terbuka tangan', nengah nyepur 'hidup bermasyarakat', juluk adek 'bernama dan bergelar', dan sakai sambayan 'gotong royong'.

\section{Kopiah Emas}

Kopiah emas digunakan oleh mempelai laki-laki, sama halnya dengan siger pada wanita. Kopiah emas terbuat dari kuningan berbentuk bulat keatas dengan ujung beruji tajam. Selain untuk pengantin pria, kopiah emas juga biasa dipakai oleh para pria muda pada saat mereka menari di balai adat.

\section{Bulan Temenggal}


Bulan temenggal merupakan hiasan dari kuningan berbentuk menyerupai tanduk tanpa motif, hanya bertatah dasar. Mulan temanggul biasanya berupa rangkaian tiga buah keping yang dirangkai dengan rantai. Cara memakainya dengan menggantung di leher sehingga tampak bergantung di bawah dada atau di atas kain sesapur.

Makna dan filosofi kalung bulan temenggal memiliki arti bulan yang purnama yang bermaksud si pemakai dapat menyinari alam sekitar dengan teduh atau damai.

\section{Buah Jukun}

Buah jukun merupakan hiasan berbentuk buah-buah kecil di atas kain yang dirangkai menjadi untaian bunga dengan benang dijadikan kalung panjang. Buah jukun biasa dipakai melingkar dari bahu ke bagian perut sampai ke belakang.

Selempang pinang buah jukun memiliki makna sebagai alat pertahanan dari orang yang berbuat jahat atau sebagai alat tolak balak. Dalam kehidupan, banyak perilaku manusia yang iri dengki dan akan melakukan hal-hal yang tidak terpuji. Harapan jika memakai selempang pinang buah jukun segala kejahatan akan hilang.

\section{Bebe}

Bebe merupakan sulaman dari kain halus yang berlubang-lubang yang bagian pinggirnya bermotif bunga. Di atas sulaman tersebut diberi payet warna putih. Perlengkapan ini biasanya dipakai dengan cara merekatkan pada bagian bahu dengan posisi di atas gelang burung.

Makna dan filosofi bebe adalah kain bersulam usus penutup bahu menghindari segala penyakit yang mudah datang dalam tubuh manusia. Bagi etnis Lampung, kepercayaan animisme pada zaman terdahulu sangat kental sekali. Walaupun terkadang kita yang memiliki berpikir terkadang hal itu tidak logis.

\section{Gelang Kano}

Gelang kano adalah gelang lengan yang dikenakan pada lengan kanan atas dan pergelangan tangan pengantin pria maupun wanita. Gelang ini terbuat dari bahan kuningan berukir berbentuk bulat dan lebih besar dibanding gelang biasa.

Makna dan filosofi gelang kano bentunya bulat maknanya agar si pemakai bisa menyatukan keluarga atau membulatkan keluarga tidak bercerai berai. Dalam berkeluarga, tentunya banyak halangan dan rintangan cobaan yang sangat berat. Jika kedua pengantin sudah memakai gelang kano, mudah-mudahan mereka bisa bersatu dan menyatukan dalam kehidupan mereka dan keluarga.

\section{Bulu Serati dan Pending}

Bulu serati merupakan ikat pinggang yang terbuat dari kain beludru yang dilapisi kain merah. Kain beludru ini kemudian dikombinasikan dengan pending, yaitu ikat pinggang yang terbuat dari uang ringgitan Belanda bergambar Ratu Wihelmina.

Makna dan filosofi Ikat pinggang bulu serati adalah untuk menyempurnakan ikatan perkawinan atau sebagai pengikat. Kemudian bulu serati juga bermaksud dan berfungsi melindungi badan bagian dalam. Pada zaman terdahulu masyarakat masih banyak menganut kepercayaan hal-hal yang gaib dan roh-roh yang jahat. Ikat pinggang bulu serati digunakan agar terhindar dari roh-roh yang jahat.

\section{Rambai Ringgit}

Rambai ringgit adalah uang riggit Belanda bergambar Ratu Belanda yang dirangkaikan dengan peniti dan kain. Biasanya digantung melingkari kain tapis bagian bawah yang dikenakan pengantin wanita. Rambai ringgit juga biasa digantungkan melingkari sesapur (baju kurung pengantin wanita).

\section{Buah Manggus}

Buah manggus berbentuk bulat seperti permainan yang terbuat dari bahan kuningan, memiliki ornamen, dan berantai kecil yang berfungsi sebagai alat pegangan. Perlengkapan ini biasa dipegang oleh pengantin wanita dan pengantin pria pada saat acara perkawinan adat.

Makna dan filosofi buah manggus sebagai tempat atau wadah untuk perhiasan dan untuk membersihkan badan dari keringat (kosmetik, sapu tangan, dan kunci). 


\section{Gelang Burung}

Gelang burung terbuat dari bahan kuningan, dibentuk menyerupai burung bersayap yang diikatkan pada bagian lengan di bawah bahu, baik itu di sebelah kiri atau kanan. Gelang ini biasa digunakan oleh mempelai pria maupun wanita.

Makna dan filosofi gelang burung adalah pemakai masih memiliki kebebasan dalam berbicara, berpendapat, dan bersikap. Dalam pemakaian gelang burung tidak sembarangan memakainya. Jika pemakaian gelang burung arah ke atas menandakan bahwa si pemakai adalah keluarga yang terhormat atau juga dapat dikatakan terpandang. Begitu juga letak arah gelang burung ke bawah mengisyaratkan si pemakai adalah masyarakat biasa.

\section{Keris}

Keris adalah senjata tradisional yang terbuat dari tempaan besi dalam bentuk berliku (iluk) dan ujungnya runcing. Gagang keris berbentuk melengkung. Sarung keris terbuat dari lempengan kuningan yang dihiasi dengan berbagai ornamen.

\section{Kanduk}

Kanduk adalah sejenis mahkota yang tidak lengkap. Kanduk memiliki jeruji tajam, terbuat dari bahan kuningan, dan bertahtakan hiasan bunga pada bagian atasnya. Selain pengantin perempuan, kanduk juga biasa dipakai oleh para wanita yang sudah bersuami pada saat mengiringi pengantin pria dan wanita.

Dilihat dari bahan maupun motif hiasan yang ada pada perlengkapan pakaian adat Lampung Pepadun, tampaklah bahwa pada zaman dahulu kala orang Lampung sudah dipengaruhi oleh kebudayaan Hindu, kebudayaan Dongson, maupun kebudayaan Belanda. Kebudayaan Hindu tampak dalam pemakaian motif burung. Selain dari keris, pengaruh budaya Dongson tampak pada pemakaian bahan pembuat perlengkapan tersebut yang rata-rata berasal dari perunggu. Sementara kebudayaan Belanda dapat dilihat dengan adanya pemakaian uang ringgit bergambar Ratu Wilhemina.

Satu hal yang menarik untuk dicatat adalah meskipun perlengkapan pengantin tersebut mengandung pengaruh dari bangsa dan agama lain, masyarakat Lampung yang kini sebagian besar beragama Islam masih memakai perlengkapan tersebut pada saat upacara pernikahan yang digelar dengan cara adat Lampung dan syariat Islam.

\section{SIMPULAN}

Setelah dikaji, terdapat makna simbolik pada tiap-tiap aksesori yang dikenakan pada pakaian adat Pepadun, di antaranya: (1) Siger yang melambangkan bahwa Lampung dialiri sembilan sungai besar; (2) Serajo Bulan bermakna kedudukan tinggi, lima kerajaan yang penah ada di Lampung, dan lima falsafah hidup masyarakat Lampung; (3) Kopiah Emas; (4) Bulan Temenggal bermakna bulan purnama yang penuh kedamaian; (5) Buah Jukun bermakna alat pertahanan; (6) Kanduk; (7) Gelang Kano bermakna mempersatukan keluarga agar utuh; (8) Keris; (9) Pending; (10) Rambai Ringgit; (11) Buah Manggus bermakna wadah sebagai pembersihan dari kotoran; (12) Gelang Burung bermakna kebebasan dalam beropini; (13) Bulu Serati sebagai penyempurnaan ikatan perkawinan; dan (14) Bebe bermakna kain pelindung dari berbagai penyakit.

\section{DAFTAR PUSTAKA}

Andriansyah. (2017). Makna pakaian dan atribut pernikahan adat Lampung dan hubungannya dengan sistem gelar atau adok dalam masyarakat adat Saibatin marga Way Lima Jurai Seputih. Universigas Lampung.

Creswell, J. W. (1998). Qualitative inquiry and research design: Choosing Among five traditions. Sage Publications, Inc. 
Effendy, O. U. (1989). Kamus komunikasi. Bandung: Mandar Maju.

Khalik, A. T. (2003). Begawi cakak pepadun dalam adat istiadat migou pak tulangbawang Lampung. Bandar Lampung: IAIN Raden Intan.

Mulyana, D. (2013). Metodologi penelitian kualitatif. Rosda.

Oyos Saroso HN. (n.d.). Tapis: An everlasting beauty.

Ramulyo, M. I. (1996). Hukum perkawinan Islam. Jakarta: Bumi Aksara. 